\section{Pseudomonas maltophilia infections in neutropenic patients and the use of imipenem}

Sir,

Febrile episodes in profoundly neutropenic patients in the absence of a bacteriological diagnosis require empirical therapy with broad spectrum antimicrobials. In many centres this initial therapy comprises a combination of a $\beta$ lactam (ureidopenicillin or extended spectrum cephalosporin) and an aminoglycoside.' Recently, the new antibiotic, imipenem ( $n$ formimidoyl thienamycin), has been advocated as sole therapy in this condition. ${ }^{2}$ Although this antibiotic has activity against a very large number of bacteria, strains of Pseudomonas (Xanthomonas) maltophilia are usually not susceptible to this agent. ${ }^{3}$

Pseudomonas maltophilia is increasingly recognized as an opportunistic pathogen in immuno-compromised patients and is associated in these individuals with a wide variety of infections, including septicaemia. ${ }^{4}$ Recently, we have seen 9 episodes of septicaemia caused by this bacterium, one in association with ecthyma gangrenosum. Seven female patients all with haematological malignancies were affected. Biochemical typing, antibiograms and epidemiological data suggested that a common infecting strain was not involved. All 9 isolates were resistant to imipenem; however, 6 were susceptible to all aminoglycoside antibiotics. The 3 strains resistant to aminoglycoside antibiotics were susceptible to ceftazidime. Only one patient had received imipenem prior to the septicaemic episode observed.

The increasing frequency of $P$ s. maltophilia infections in debilitated patients ${ }^{5}$ may limit the use of imipenem in the empirical therapy of febrile episodes. In addition, the use of imipenem in such patients for the treatment of other infections may select for the carriage of $P S$. maltophilia in the gastrointestinal tract and other sites, such as respiratory tract. ${ }^{6}$ During episodes of profound neutropenia Ps. maltophilia colonizing such patients may then cause septicaemia which will not be adequately treated with imipenem. For example, Bodey et al. ${ }^{2}$ describe a case of intercurrent septicaemia due to this organism in a cancer patient receiving imipenem. As only one of our patients received imipenem before developing septicaemia, it may be that other antibiotics select for gut carriage or that Ps. maltophilia is more commonly present in the gut flora than previously supposed.

Currently, we are investigating the faecal carriage of this organism in patients with and without haematological malignancies and the effect of imipenem on this carriage.

K.G. Kerr P.M. Hawkey

J.A. Child

D.R. Norfolk ${ }^{2}$

A.W. Anderson

'Department of Microbiology. University of Leeds Leeds, LS2 9JT

${ }^{2}$ Department of Haematology

The General Infirmary at Leed Leeds, LS1 $3 E X$ and

${ }^{3}$ Department of Microbiology, York District Hospital, York YO3 $7 \mathrm{HE}, \mathrm{UK}$

\section{References}

1. de Pauw, B.E. Antibacterial therapy in the immunocompromised host. Curr Opin Infect Dis 1989, 2: 561-567.

2. Bodey, G.P., Alvarez, M.E., Jones, P.G., Rolston, K.V., Steelhammer, L. \& Fainstein, V. Imipenem-cilastatin as initial therapy for febrile cancer patients. Antimicrob Agents Chemother 1986, 30: 211-214.

3. Kahan, F.M., Kropp, H., Sundelof, J.G. \& Brinbaum, J Thienamycin: development of imipenem-cilastatin. $J$ Anti microb Chemother 1983, 12 (Suppl D): 1-35.

4. Zuravleff, J.J. \& Yu, V.L. Infections caused by Pseudomonas maltophilia with emphasis on bacteraemia. Case report and a review of the literature. Rev Infect Dis 1982, 4: 1236-1246.

5. Muder, R.R., Yu, V.L., Dummer, J.S., Vinson, C. \& Lumish, R.M. Infections caused by Pseudomonas maltophilia. Arch Intern Med 1987, 147: 1672-1674.

6. Diaz-Mitoma, F., Harding, G.K., Louie, T.J., Thanson, M., James, M. \& Ronald, A.R. Prospective randomised comparison of imipenem-cilastatin and cefotaxime for treatment of lung, soft tissue and renal infections. Rev Infect Dis 1985, 7 (Suppl 3): S452-S457. 